\title{
Acute Toxicity Study of Standardized Mitragyna speciosa Korth Aqueous Extract in Sprague Dawley Rats
}

\author{
Mohd Saleh Ahmad Kamal ${ }^{1}$, Ahmad Rohi Ghazali ${ }^{2}$, Noral Ashikin Yahya ${ }^{1}$, Mohd Isa Wasiman ${ }^{1} \&$ Zakiah \\ Ismail $^{1}$ \\ ${ }^{1}$ Herbal Medicine Research Center, Institute for Medical Research, Kuala Lumpur, Malaysia \\ ${ }^{2}$ Biomedical Science Department, Faculty of Allied Health Sciences, National University of Malaysia, Kuala \\ Lumpur, Malaysia \\ Correspondence: Ahmad Rohi Ghazali, Biomedical Science Department, Faculty of Allied Health Sciences, \\ National University of Malaysia, Kuala Lumpur, Malaysia. Tel: 60-162-744-646. E-mail: \\ rohighazali@yahoo.co.uk
}

Received: February 28, 2012 Accepted: April 12, 2012 Online Published: August 15, 2012

doi:10.5539/jps.v1n2p120 URL: http://dx.doi.org/10.5539/jps.v1n2p120

The research is financed by a grant from the Ministry of Health, Malaysia (Reference number: JPP-IMR 07-007)

\begin{abstract}
Mitragyna speciosa Korth (MS) leaves are popularly used in Thailand and Malaysia. The leaves are used as a medicinal agent for treating diarrhea, worm infestations and acts as an analgesic and antipyretic agents. The present study investigated the acute toxicity of standardized MS leaf aqueous extract on Sprague Dawley rats at 175,500 and $2000 \mathrm{mg} / \mathrm{kg}$ body weight. Dose selection was based on the Up-and-down procedure (OECD 425). No death was observed. The single oral dose of the extract also had no significant changes in the body weight, food and water consumption. The relative weights of the internal organs were also normal. However, the mean corpuscular hemoglobin concentration, albumin, calcium and cholesterol were significantly decreased. Histological examination showed steatosis and centrilobular necrosis only on several parts of the liver for the treated group. In short, the standardized MS aqueous extract did not cause any lethality and only caused slight toxic effects.
\end{abstract}

Keywords: acute toxicity, standardized aqueous extract, Mitragyna speciosa Korth, medicinal plants, toxicological profile

\section{Introduction}

Herbal preparations can be formulated into many forms of proprietary medicines including liquids and they have been used world-wide for thousands of years (Deng, 2002). Based on their traditional use since ancient times, they are often assumed to be safe. However, frequent use of medicinal herbs can increase the risk of toxicity as medicinal herbs can also cause toxic, carcinogenic and teratogenic effects on human (Wooley, 2003). Thus, it is important to document the toxicological data comprehensively for all medicinal plants for their safety reasons.

Mitragyna speciosa Korth (MS), is a plant that originates from South East Asia and is found mainly in Thailand and Malaysia (Wiart, 2002) and it has been used in traditional medicine for decades. The leaf of MS (kratom in Thailand) was used in Thailand for its opium-like effect and coca-like stimulant ability to counter fatigue and enhance tolerance to work hard under a scorching sun (Matsumoto et al., 2004). Local people also used it to alleviate pain, coughing or diarrhea (Kumarnsit et al., 2007). In Malaysia, a decoction of the MS leaves is taken to overcome drug addiction (Ong \& Nordiana, 1999). The leaves were processed and used as a substitute for opium in peninsular Malaysia (Chan et al., 2005). Local media in Malaysia has also reported that traditional healers would use ketum to wean heroin addiction, to de-worm, to cure diarrhea, to improve blood circulation and even to treat diabetes (Chan et al., 2005).

However, study showed that ketum users can also become addicted. Hostility, aggression, excessive tearing, inability to work, aching of muscles and bones and the jerky movement of limbs are the examples of its typical withdrawal symptoms. It was also reported in the study that anorexia, weight loss and insomnia were common among long-term ketum addicts (Suwanlert, 1975). Previous study also showed that the exposure of Mitragyna 
speciosa Korth on human cell caused cytotoxic dependent dose effect which prevents profileration in all examined cells at concentration more than $100 \mu \mathrm{g} / \mathrm{ml}$ with substantial cell death at more than $1000 \mu \mathrm{g} / \mathrm{ml}$ on adherent HEK 293 and SH-SY5Y cells (Saidin \& Gooderham, 2007). Notwithstanding the widespread use of MS in traditional medicine, there is still insufficient data about its toxicity. Therefore, the aim of the present study was to evaluate and document the acute toxic effects of the standardized MS aqueous extract in Sprague Dawley rats.

\section{Methodology}

\subsection{Test Article and Standardization}

Test article was supplied by the Toxicology and Pharmacology Unit at the Herbal Medicinal Research Center, Kuala Lumpur, Malaysia. MS leaves were collected at Berjuntai Bestari, Selangor, Malaysia. A sample of test article, MS (Voucher No: RM 0108) was received and stored at the Institute of Medical Research (IMR), Kuala Lumpur, Malaysia. Leaves were extracted using aqueous extraction (Houghton \& Raman, 1998). The standardization of Mitragyna speciosa Korth aqueous extract was confirmed by using gas chromatography-mass spectrometer machine, Agilent 5973, Agilent Technologies Inc, US. Mitragynine compound was used as standard in this confirmation which is extracted from previous ketum leaves. Identity and purity extract was verified by comparison between chromatogram peak of Mitragyna speciosa Korth aqueous extract and mitragynine compound. We successfully found out that chromatogram peak of Mitragyna speciosa Korth extract has the same peak with chromatogram peak of mitrgaynine compund for mass spectrometer value. $100 \mathrm{~g}$ of Mitragyna speciosa Korth crude extract can produce $18 \pm 2$ g Mitragyna speciosa Korth aqueous extract with $18 \pm 2 \%$ of production percentage. The test article was stored at $4^{\circ} \mathrm{C}$ until further use.

\subsection{Test System and Husbandry}

Healthy young adult male and female Sprague Dawley (SD) rats were used in this study. At the commencement of its dose, each animal should be between 8 and 12 weeks old and its weight should fall in an interval within \pm $20 \%$ of the mean initial weight of any previously dosed animals. The animals were obtained from the Laboratory Animal Resources Unit, Medical Resource Research Center, Institute for Medical Research (IMR), Kuala Lumpur. The experimental protocol was approved by the Animal Care and Use Committee (ACUC) of IMR (ACUC/KKM/02(7/2008). They were housed one rat per cage and maintained in standard environmental conditions $\left(22 \pm 3{ }^{\circ} \mathrm{C} ; 12: 12 \mathrm{~h}\right.$ dark/light cycle). All rats were fed with certified rodent food (Rodent Diet Specialty Feeds, Glen Forrest, Western Australia) and drinking water was available ad libitum. The experimental animals were acclimatized for at least 5 days before the commencement of the study and labeled appropriately.

\subsection{Acute Toxicity Study}

Acute oral toxicity test was carried out according to the Organization for Economic Co-operation and Development (OECD) guidelines for Testing of Chemicals Number 425 (OECD, 2001) Up-and-Down Procedure with slight modifications. The acute toxicity study comprised four groups, one control and three treatment groups that consisted of 5 male and 5 female rats in each group to make the statistical analysis more accurate. Animals were fasted prior to dosing and after the period of fasting, the animals were weighed. The dose was calculated and the test substance administered according to the fasted body weight (BW) of each animal (Table 1). The LD50 or median lethal oral dose, which is a statistically derived single dose of a substance that can be expected to cause death in 50 per cent of animals when administered by the oral route will be determined. The LD50 value is expressed in terms of weight of test substance per unit weight of test animal $(\mathrm{mg} / \mathrm{kg})$. Dosing for this study was initiated at $175 \mathrm{mg} / \mathrm{kg}$ because there was no estimate of the substance's lethality available.

Table 1. Body weight $(\mathrm{g})$ of female and male rats recorded after fasting period

\begin{tabular}{lll}
\hline & \multicolumn{2}{c}{ Body weight $(\mathrm{g})$} \\
\cline { 2 - 3 } & Female & Male \\
\hline Control & $159.70 \pm 14.18$ & $196.80 \pm 11.03$ \\
$175 \mathrm{mg} / \mathrm{kg}$ & $167.18 \pm 20.05$ & $214.66 \pm 18.23$ \\
$500 \mathrm{mg} / \mathrm{kg}$ & $159.68 \pm 17.81$ & $190.38 \pm 9.83$ \\
$2000 \mathrm{mg} / \mathrm{kg}$ & $165.94 \pm 7.78$ & $210.70 \pm 11.50$ \\
\hline
\end{tabular}


The first animal group was dosed a step below the best preliminary estimate of the LD50 which was $175 \mathrm{mg} / \mathrm{kg}$. This was to make sure that LD50 value could be determined correctly without more pain and suffering on rats. Because the animal in the first group survived, the second animal group received a higher dose of $500 \mathrm{mg} / \mathrm{kg}$. The dose progressed to a maximum dose of $2000 \mathrm{mg} / \mathrm{kg}$. A dose progression factor of 3.2 should be used in this study but the second dose at $500 \mathrm{mg} / \mathrm{kg}$ was used because it is not too high or too low as acute dose and to make dose calculation more accurate. The test article was administered orally to all rats except those in the control group. The control group received drinking water orally once, at volumes of $0.175,0.5$ and $2 \mathrm{ml}$ using an intubation needle. The treatment group received standardized MS aqueous extract that was diluted in drinking water which is vehicle at doses of 175,500 and $2000 \mathrm{mg} / \mathrm{kg}$ BW given orally once, also at volumes of $0.175,0.5$ and $2 \mathrm{ml}$ using an intubation needle. All rats were observed individually for a total of 14 days, except where they had to be removed from the study and humanely killed for animal welfare reasons or were found dead. Clinical observations were made once a day for mortality, moribund, ill health or reaction to treatment.

\subsection{Body Weight, Food and Water Consumption}

The body weight (BW) of each rat was recorded once weekly and the differences of the BW were noted. The amount of food and water consumed was measured weekly from the quantity of food and water supplied and the amount remaining after 24 hours for 2 weeks of the study period.

\subsection{Hematological and Biochemical Analysis}

On the necropsy day, blood was drawn through cardiac puncture (or whenever possible) from the posterior vena cava of all rats under ether anesthesia. The blood was placed into EDTA bottles for hematological assay and in plain bottle for clinical biochemistry determination. The blood for hematological assay was immediately analyzed using a hematological analyzer (Medonic CA 620, Clinical Diagnostic Solutions Inc., U.S.A). The parameters measured were mean corpuscular hemoglobin concentration (MCHC), red blood cell (RBC), mean cell volume (MCV), red blood cell distribution (RDW), hematocrit (HCT), platelets (PLT), mean corpuscular volume (MPV), white blood cell (WBC), hemoglobin (HGB) and mean corpuscular hemoglobin (MCH). The blood in the plain bottle was allowed to stand for a minimum of 3 hours for complete clotting. The serum were collected and transferred to another tube to be centrifuged at $4000 \mathrm{rpm}$ at $4^{\circ} \mathrm{C}$ for 10 minutes. The serums were then kept at $-20^{\circ} \mathrm{C}$ until analysis for clinical biochemistry measurements using the Vitalab Selecta, E-series, Netherlands. Clinical Biochemistry values determination were for liver profile such as albumin, total protein, alkaline phosphatase (ALP) and alanine aminotransferase (ALT). Renal profile parameters measured were urea, creatinine and calcium. Creatinine kinase $(\mathrm{CK})$ was the cardiac profile parameters and other biochemistries were glucose and amylase, cholesterol for lipid profile.

\subsection{Relative Organ Weight (ROW)}

All control and treatment rats were sacrificed using an overdose of ether on Day 15. A comprehensive gross observation was carried out on the internal organs namely the liver, kidney, spleen, heart, lung, ovary, adrenal and brain. They were observed for any signs of abnormality and presence of lesions. The organs were then carefully dissected, cleaned of any fats and weighed (absolute weight). The relative organ weight (ROW) of each organ was then calculated according to the following equation:

$$
\text { ROW }=\left(\frac{\text { Absolute organ weight }(\mathrm{g}) \times 100}{\text { Body weight of rat on sacrifice day }(\mathrm{g})}\right)
$$

Each organ was then preserved in $10 \%$ buffered formalin for subsequent histopathological examination. The tissues were embedded in paraffin, and then sectioned, stained with haematoxylin and eosin before fixed as slices and were examined microscopically.

\subsection{Statistical Analysis}

All findings such as body weight changes, food and water consumption, haematology and blood chemistry were tabulated and analyzed. Data are expressed in the mean \pm and standard deviation. The mean value (x) and standard deviation (SD) were calculated for each variable measured and analyzed statistically by analysis of variance (ANOVA) to determine significant differences between groups at $\mathrm{p}<0.05$. The analysis and comparison were evaluated for significance at $5 \%(a=0.05)$ (Hinton et al., 2004).

\section{Results}

\subsection{Physical Observation and Mortality}

The acute toxicity study did not result in any mortality of the treated rats. Therefore, we cannot determine LD50 
from the study. We can estimate that the LD50 value was higher than $2000 \mathrm{mg} / \mathrm{kg}$. There were signs of fatigue and sleep for male rats while only a sign of fatigue was detected on female rats at the highest dose of extract. No toxic effects other than fatigue and sleep signs were observed throughout the 14 day study period. Physical observation of the test article-treated rats throughout the study indicated that none of them showed signs of toxic effects such as changes in skin and fur, eyes and mucous membrane, behavior pattern, tremors, salivation, diarrhea and coma. No mortality was also observed in any of the rats.

\subsection{Body Weight, Food and Water Consumption}

The body weight of the treatment and control rats were as shown in Table 2 and Table 3 respectively. There were gradual increase in body weight of the treatment and control rats. The body weight of the treatment rats were not significantly different compared to the control rats. The food and water consumption of the treatment rats were also not significantly different compared to the control rats measured throughout the study (Table 2 and Table 3).

Table 2. Body weight $(\mathrm{g})$, food consumption $(\mathrm{g})$ and water intake $(\mathrm{mL})$ by control and female rats treated with standardized MS aqueous extract recorded during acute toxicity study

\begin{tabular}{lllllll}
\hline & \multicolumn{2}{l}{ Body weight $(\mathrm{g})$} & \multicolumn{2}{l}{ Food consumption $(\mathrm{g})$} & \multicolumn{2}{l}{ Water intake $(\mathrm{ml})$} \\
\cline { 2 - 7 } & Week 1 & Week 2 & Week 1 & Week 2 & Week 1 & Week 2 \\
\hline Control & $192.18 \pm 21.56$ & $215.76 \pm 25.04$ & $268.02 \pm 15.47$ & $281.28 \pm 9.98$ & $320 \pm 43.16$ & $327 \pm 28.64$ \\
$175 \mathrm{mg} / \mathrm{kg}$ & $202.52 \pm 20.79$ & $226.56 \pm 22.10$ & $254.2 \pm 6.40$ & $276 \pm 12.16$ & $289 \pm 12.45$ & $282 \pm 27.97$ \\
$500 \mathrm{mg} / \mathrm{kg}$ & $190.58 \pm 20.06$ & $214.26 \pm 24.49$ & $265.06 \pm 10.13$ & $281.98 \pm 8.66$ & $339 \pm 14.32$ & $319 \pm 23.56$ \\
$2000 \mathrm{mg} / \mathrm{kg}$ & $197.88 \pm 13.92$ & $222.26 \pm 18.93$ & $263.4 \pm 8.47$ & $278.52 \pm 15.11$ & $323 \pm 35.99$ & $314 \pm 24.85$ \\
\hline
\end{tabular}

Group given $175 \mathrm{mg} / \mathrm{kg}, 500 \mathrm{mg} / \mathrm{kg}$ and $2000 \mathrm{mg} / \mathrm{kg} \mathrm{BW}$ of standardized MS aqueous extract single dose orally and observed for 14 days. Values are expressed as mean \pm standard deviation, $\mathrm{n}=5$. ${ }^{*} \mathrm{p}$ value less than 0.05 , $(\mathrm{p}<$ 0.05 ) significant value.

Table 3. Body weight $(\mathrm{g})$, food consumption $(\mathrm{g})$ and water intake $(\mathrm{mL})$ by control and male rats treated with standardized MS aqueous extract recorded during acute toxicity study

\begin{tabular}{lllllll}
\hline \multicolumn{2}{c}{ Body weight $(\mathrm{g})$} & \multicolumn{2}{l}{ Food consumption $(\mathrm{g})$} & \multicolumn{2}{l}{ Water intake $(\mathrm{ml})$} \\
\hline & Week 1 & Week 2 & Week 1 & Week 2 & Week 1 & Week 2 \\
\hline Control & $253.36 \pm 9.62$ & $290.02 \pm 18.1$ & $155.92 \pm 8.83$ & $143.72 \pm 13.11$ & $196.8 \pm 17.92$ & $186 \pm 30.01$ \\
$175 \mathrm{mg} / \mathrm{kg}$ & $274.56 \pm 26.2$ & $316.6 \pm 31.06$ & $166.94 \pm 11.98$ & $160.48 \pm 18.41$ & $208 \pm 30.85$ & $208 \pm 53.26$ \\
$500 \mathrm{mg} / \mathrm{kg}$ & $247.3 \pm 12.92$ & $290.34 \pm 18.31$ & $154.16 \pm 9.39$ & $150.64 \pm 13.72$ & $202.2 \pm 30.65$ & $206 \pm 35.74$ \\
$2000 \mathrm{mg} / \mathrm{kg} 277.52 \pm 22.85$ & $320.6 \pm 28.17$ & $172.32 \pm 22.86$ & $161.84 \pm 22.91$ & $236.4 \pm 45.42$ & $225.6 \pm 40.78$ \\
\hline
\end{tabular}

Group given $175 \mathrm{mg} / \mathrm{kg}, 500 \mathrm{mg} / \mathrm{kg}$ and $2000 \mathrm{mg} / \mathrm{kg} \mathrm{BW}$ of standardized MS aqueous extract single dose orally and observed for 14 days. Values are expressed as mean \pm standard deviation, $\mathrm{n}=5$. ${ }^{*} \mathrm{p}$ value less than 0.05 , $(\mathrm{p}<$ $0.05)$ significant value.

\subsection{Haematological and Clinical Biochemistry}

Haematology and clinical biochemistry data are presented in Table 4 and 5 respectively. Haematological values measured showed a significant decrease of MCHC level for female rats with $\mathrm{p}<0.05$ in $500 \mathrm{mg} / \mathrm{kg}$ and 2000 $\mathrm{mg} / \mathrm{kg}$ treatment group. Other haematology values, RBC, MCV, RDW, HCT, PLT, MPV, WBC, HGB and MCH for female rats were not significantly different as compared to the control rats. All haematological values for male rats were not significantly different also compared to the control rats and they remained within the normal limits (control values). All clinical biochemistry values of female rats were also not significantly different as compared to the control rats and they remained within normal limits (control values). However, the clinical biochemistry values of albumin, calcium and cholesterol decreased in the $175 \mathrm{mg} / \mathrm{kg}$ treatment group for male rats as compared to the control rats, with $\mathrm{p}<0.05$ (Table 5). The level of calcium change cannot produce tetany or the risk of changes of excitability of excitable cell such as neuron and muscle. Other clinical biochemistry parameters measured for male rats such as total protein, ALP, ALT, urea, creatinine, CK, glucose and amylase 
were not significantly different compared to the control.

Table 4. Haematological values of control and rats treated with standardized MS aqueous extract measured during the acute toxicity study

\begin{tabular}{|c|c|c|c|c|c|c|c|c|}
\hline Haematology & \multicolumn{4}{|c|}{ Female Rats } & \multicolumn{4}{|c|}{ Male Rats } \\
\hline \multicolumn{9}{|l|}{ Parameters } \\
\hline Measured & Control & $175 \mathrm{mg} / \mathrm{kg}$ & $500 \mathrm{mg} / \mathrm{kg}$ & $2000 \mathrm{mg} / \mathrm{kg}$ & Control & $175 \mathrm{mg} / \mathrm{kg}$ & $500 \mathrm{mg} / \mathrm{kg}$ & $2000 \mathrm{mg} / \mathrm{kg}$ \\
\hline $\mathrm{MCHC}(\mathrm{g} / \mathrm{dL})$ & $43.70 \pm 0.37$ & $43.62 \pm 0.37$ & $42.86 \pm 0.44 *$ & $42.76 \pm 0.58 *$ & $41.60 \pm 0.80$ & $40.90 \pm 0.25$ & $40.95 \pm 0.75$ & $41.70 \pm 0.22$ \\
\hline $\operatorname{RBC}\left(10^{6} / \mathrm{mm}^{3}\right)$ & $7.20 \pm 0.30$ & $7.43 \pm 0.20$ & $7.48 \pm 0.22$ & $7.40 \pm 0.27$ & $6.67 \pm 0.29$ & $6.87 \pm 0.30$ & $6.46 \pm 0.44$ & $5.54 \pm 2.57$ \\
\hline $\operatorname{MCV}\left(\mu \mathrm{m}^{3}\right)$ & $52.86 \pm 1.54$ & $52.72 \pm 1.25$ & $52.30 \pm 1.06$ & $52.96 \pm 1.06$ & $54.30 \pm 0.66$ & $55.26 \pm 1.43$ & $55.43 \pm 1.39$ & $54.10 \pm 0.87$ \\
\hline RDW (\%) & $13.28 \pm 0.73$ & $13.86 \pm 0.58$ & $13.94 \pm 1.14$ & $14.12 \pm 0.64$ & $13.84 \pm 0.86$ & $13.44 \pm 0.44$ & $13.58 \pm 0.49$ & $12.44 \pm 2.13$ \\
\hline HCT (\%) & $38.04 \pm 0.65$ & $39.20 \pm 1.41$ & $39.16 \pm 1.52$ & $39.18 \pm 1.88$ & $36.20 \pm 1.76$ & $37.96 \pm 1.17$ & $35.83 \pm 2.95$ & $30.14 \pm 14.06$ \\
\hline $\operatorname{PLT}\left(10^{3} / \mathrm{mm}^{3}\right)$ & $862.40 \pm 56.83$ & $891.40 \pm 87.08$ & $878.80 \pm 80.33$ & $850.60 \pm 58.89$ & $678.60 \pm 49.65$ & $719.20 \pm 64.13$ & $645.25 \pm 85.87$ & $658.25 \pm 67.92$ \\
\hline $\operatorname{MPV}\left(\mu \mathrm{m}^{3}\right)$ & $6.56 \pm 0.15$ & $6.78 \pm 0.33$ & $6.56 \pm 0.22$ & $6.74 \pm 0.19$ & $6.26 \pm 0.13$ & $6.42 \pm 0.22$ & $6.28 \pm 0.15$ & $6.32 \pm 0.28$ \\
\hline $\operatorname{WBC}\left(10^{3} / \mathrm{mm}^{3}\right)$ & $4.34 \pm 0.76$ & $5.92 \pm 1.54$ & $5.56 \pm 0.92$ & $6.26 \pm 1.61$ & $4.88 \pm 0.97$ & $5.76 \pm 3.09$ & $4.93 \pm 2.13$ & $5.56 \pm 3.71$ \\
\hline $\mathrm{HGB}(\mathrm{g} / \mathrm{dL})$ & $16.60 \pm 0.32$ & $17.06 \pm 0.54$ & $16.78 \pm 0.62$ & $16.74 \pm 0.58$ & $15.04 \pm 0.50$ & $15.52 \pm 0.41$ & $14.68 \pm 1.09$ & $12.54 \pm 5.89$ \\
\hline $\mathrm{MCH}$ (pg) & $23.06 \pm 0.55$ & $22.98 \pm 0.50$ & $22.44 \pm 0.38$ & $22.62 \pm 0.36$ & $22.54 \pm 0.36$ & $22.60 \pm 0.60$ & $22.70 \pm 0.69$ & $22.56 \pm 0.43$ \\
\hline
\end{tabular}

Group given $175 \mathrm{mg} / \mathrm{kg}, 500 \mathrm{mg} / \mathrm{kg}$ and $2000 \mathrm{mg} / \mathrm{kg} \mathrm{BW}$ of standardized MS aqueous extract single dose orally and observed for 14 days. Values are expressed as mean \pm standard deviation, $\mathrm{n}=5 .{ }^{*} \mathrm{p}$ value less than 0.05 , $(\mathrm{p}<$ 0.05): significant value, MCHC; mean corpuscular hemoglobin concentration, RBC; red blood cell, MCV; mean cell volume, RDW; red blood cell distribution, HCT; hematocrit, PLT; platelets, MPV; mean corpuscular volume, WBC; white blood cell, HGB; hemoglobin, $\mathrm{MCH}$; mean corpuscular hemoglobin.

Table 5. Clinical biochemistry values of control and rats treated with standardized MS aqueous extract measured during the acute toxicity study

\begin{tabular}{|c|c|c|c|c|c|c|c|c|}
\hline \multirow{2}{*}{$\frac{\text { Blood/serum }}{\text { Parameters }}$} & \multicolumn{4}{|c|}{ Female Rats } & \multicolumn{4}{|c|}{ Male Rats } \\
\hline & & & & & & & & \\
\hline Measured & Control & $175 \mathrm{mg} / \mathrm{kg}$ & $500 \mathrm{mg} / \mathrm{kg}$ & $2000 \mathrm{mg} / \mathrm{kg}$ & Control & $175 \mathrm{mg} / \mathrm{kg}$ & $500 \mathrm{mg} / \mathrm{kg}$ & $2000 \mathrm{mg} / \mathrm{kg}$ \\
\hline \multicolumn{9}{|l|}{ Liver profile } \\
\hline Albumin $(g / L)$ & $29.30 \pm 5.57$ & $31.28 \pm 3.60$ & $29.84 \pm 1.78$ & $29.05 \pm 3.49$ & $29.14 \pm 3.20$ & $22.70 \pm 3.86 *$ & $26.72 \pm 4.20$ & $26.86 \pm 1.05$ \\
\hline Protein total $(g / L)$ & $53.52 \pm 11.24$ & $57.35 \pm 5.34$ & $53.26 \pm 5.67$ & $52.13 \pm 4.86$ & $42.22 \pm 5.67$ & $32.56 \pm 6.98$ & $38.12 \pm 6.76$ & $37.50 \pm 1.74$ \\
\hline $\operatorname{ALP}(\mathrm{U} / \mathrm{L})$ & $257.18 \pm 59.57$ & $272.43 \pm 84.80$ & $251.10 \pm 25.02$ & $235.53 \pm 56.40$ & $561.72 \pm 99.58$ & $479.90 \pm 148.27$ & $537.58 \pm 102.75$ & $494.20 \pm 80.96$ \\
\hline $\operatorname{ALT}(\mathrm{U} / \mathrm{L})$ & $41.00 \pm 8.70$ & $36.38 \pm 2.67$ & $42.18 \pm 5.36$ & $38.25 \pm 1.86$ & $68.14 \pm 12.67$ & $47.46 \pm 11.94$ & $64.10 \pm 17.45$ & $54.80 \pm 11.02$ \\
\hline \multicolumn{9}{|l|}{ Renal profile } \\
\hline Urea $(\mathrm{mmol} / \mathrm{L})$ & $8.06 \pm 2.13$ & $9.07 \pm 1.50$ & $7.61 \pm 0.55$ & $8.11 \pm 1.21$ & $10.95 \pm 4.17$ & $6.48 \pm 1.68$ & $8.31 \pm 1.68$ & $8.70 \pm 3.80$ \\
\hline Creatinine $(\mu \mathrm{mol} / \mathrm{L})$ & $55.80 \pm 12.03$ & $68.50 \pm 11.28$ & $59.00 \pm 4.53$ & $54.75 \pm 2.28$ & $52.75 \pm 2.63$ & $43.00 \pm 12.92$ & $48.00 \pm 6.78$ & $45.00 \pm 6.06$ \\
\hline Calcium $(\mathrm{mmol} / \mathrm{L})$ & $2.43 \pm 0.50$ & $2.64 \pm 0.36$ & $2.40 \pm 0.22$ & $2.34 \pm 0.23$ & $2.87 \pm 0.23$ & $2.17 \pm 0.66 *$ & $2.65 \pm 0.12$ & $2.61 \pm 0.14$ \\
\hline \multicolumn{9}{|l|}{ Cardiac profile } \\
\hline $\mathrm{CK}(\mathrm{U} / \mathrm{L})$ & $942.60 \pm 192.86$ & $815.00 \pm 213.89$ & $983.80 \pm 288.52$ & $1031.25 \pm 257.58$ & $8529.20 \pm 373.88$ & $620.20 \pm 218.35$ & $745.20 \pm 461.28$ & $595.60 \pm 219.56$ \\
\hline \multicolumn{9}{|l|}{ Lipid profile } \\
\hline Cholesterol $(\mathrm{mmol} / \mathrm{L})$ & $1.44 \pm 0.36$ & $1.53 \pm 0.29$ & $1.39 \pm 0.31$ & $1.29 \pm 0.31$ & $1.34 \pm 0.23$ & $0.88 \pm 0.18 *$ & $1.21 \pm 0.27$ & $1.10 \pm 0.11$ \\
\hline Glucose $(\mathrm{mmol} / \mathrm{L})$ & $11.19 \pm 4.48$ & $19.22 \pm 6.63$ & $13.06 \pm 4.01$ & $12.15 \pm 1.54$ & $7.12 \pm 2.89$ & $6.99 \pm 3.59$ & $7.82 \pm 3.36$ & $7.18 \pm 2.12$ \\
\hline Amylase (U/L) & \multicolumn{8}{|c|}{$1390.60 \pm 305.961484 .00 \pm 279.701449 .80 \pm 207.911338 .00 \pm 206.072284 .60 \pm 305.021763 .20 \pm 531.342124 .20 \pm 295.452319 .40 \pm 135.78$} \\
\hline
\end{tabular}

\subsection{Gross Necropsy}

Gross necropsy findings did not reveal significant changes in any of the organs examined. The relative organ weight per $100 \mathrm{~g}$ body weight recorded at the end of the study did not also show any significant difference as 
compared with the control group (Table 6).

Table 6. Values of control and rats treated with standardized MS aqueous extract measured during the acute toxicity study. The relative organ weight per $100 \mathrm{~g}$ body weight recorded at the end of the study

Relative organ weight in gram per $100 \mathrm{~g} \mathrm{BW}$ of control and rats treated with standardized MS aqueous extract (\%)

\begin{tabular}{|c|c|c|c|c|c|c|c|c|}
\hline \multirow[b]{2}{*}{ Organs } & \multicolumn{3}{|c|}{ Female Rats } & \multicolumn{5}{|c|}{ Male Rats } \\
\hline & 1 & $175 \mathrm{~ms}$ & & 2 & C & $\mathrm{g}$ & $\mathrm{g}$ & 2 \\
\hline Liver & & 4. & 2 & 6 & 11 & 6 & 3. & 4 \\
\hline idney Left & 3 & $0.38 \pm 0.03$ & 04 & 01 & 02 & 4 & 0. & .03 \\
\hline idney Right & & 0. & 05 & 04 & 05 & 0.3 & 03 & .02 \\
\hline idney & 6 & 0.7 & $0.85 \pm$ & 04 & 06 & .09 & 0.6 & 0.6 \\
\hline 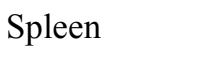 & & 0.1 & $0.20=$ & 0.1 & & 02 & & \\
\hline eart & & 0.3 & $0.34 \pm$ & 0.3 & 02 & .03 & 0.3 & \\
\hline ang & 4 & 0.5 & $0.61 \pm 0.07$ & $0.56 \pm 0.06$ & 12 & 0. & 0.4 & 0.4 \\
\hline Ovar & & & $0.03 \pm 0$ & $0.03 \pm$ & & & & \\
\hline & & & & & & & & .07 \\
\hline Ovary & & $0.05 \pm 0.00$ & $0.06 \pm 0.01$ & $0.05 \pm 0.01$ & & & & $1.10 \pm 0.14$ \\
\hline Adrenal Left & & 0.02 & $0.01 \pm 0.00$ & $0.01 \pm 0.00$ & $0.00 \pm 0.00$ & $0.00 \pm 0.00$ & 0.00 & $0.00 \pm 0.00$ \\
\hline Adrenal Right & $0.01 \pm 0.00$ & $0.01 \pm 0.00$ & $0.01 \pm 0.00$ & $0.01 \pm 0.00$ & $0.00 \pm 0.00$ & $0.00 \pm 0.00$ & $0.00 \pm 0.00$ & $0.00 \pm 0.00$ \\
\hline Adrenal & $0.03 \pm 0.00$ & $0.03 \pm 0.00$ & $0.03 \pm 0.00$ & $0.03 \pm 0.00$ & $0.01 \pm 0.00$ & $0.00 \pm 0.00$ & $0.01 \pm 0.00$ & $0.01 \pm 0.00$ \\
\hline Brain & $0.78 \pm 0.21$ & $0.73 \pm 0.06$ & $0.82 \pm 0.08$ & $0.82 \pm 0.08$ & $0.44 \pm 0.06$ & $0.45 \pm 0.05$ & $0.47 \pm 0.02$ & $0.43 \pm 0.02$ \\
\hline
\end{tabular}

Group given $175 \mathrm{mg} / \mathrm{kg}, 500 \mathrm{mg} / \mathrm{kg}$ and $2000 \mathrm{mg} / \mathrm{kg} \mathrm{BW}$ of standardized MS aqueous extract single dose orally and observed for 14 days. Values are expressed as mean \pm standard deviation, $\mathrm{n}=5$. ${ }^{*} \mathrm{p}$ value less than $0.05,(p<$ $0.05)$ significant value.
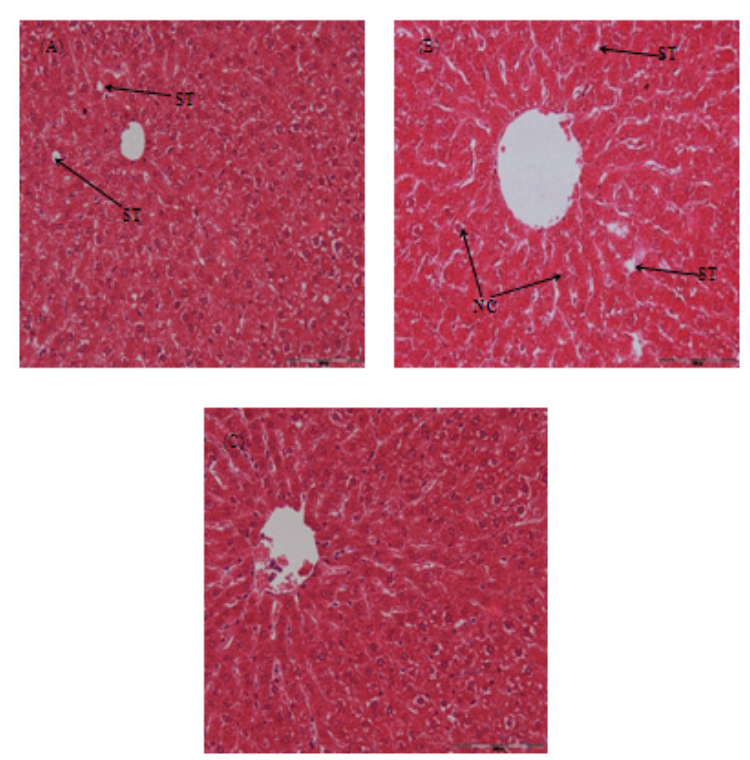

Figure 1. Liver section were stained with hematoxylin and eosin (H\&E-stained 200×) showing the effect of standardized MS aqueous extract on acute toxicity study of rats(A) Treatment group; (B) $2000 \mathrm{mg} / \mathrm{kg}$ in male rats; (C) control rats. Indicator: ST, steatosis; NC, centrilobular necrosis.

\subsection{Histopathology}

Histopathology results showed that standardized MS aqueous extract caused steatosis (ST) in all treatment 
groups for both female and male rats at several parts of the liver tissue only. Microscopic examination also showed centrilobular necrosis sign (NC) in $2000 \mathrm{mg} / \mathrm{kg}$ treatment group of male rats only. However, there were no significant morphological changes detected in other organs in all animal samples from all groups of study including renal tubules even though biochemical data for male rats also showed the significant changes of calcium level (Figure 1).

\section{Discussion}

Rural communities in Malaysia commonly use herbs as food and traditional medicine (Zakaria \& Mohd, 2010). MS aqueous extract has been used traditionally by some parts of the population as an alternative treatment for many diseases, especially to relieve drug addictions. Scientific evidence for their efficacy is widely studied but systemic safety studies are lacking. Therefore it is essential to evaluate the toxicity of the standardized MS aqueous extract in animals to ensure its safety. In the present study, both genders of rats were used to assess MS acute toxic effects. Female rats were chosen because it was the most sensitive sex to see the effect of treatment (OECD, 2001; Lipnick et al., 1995). If the study involves male rats, there must be enough justification for the use (OECD, 2001). Male rats have greater metabolic capacity than female rats such as different activities of metabolism enzymes in liver, which often leads to sex-related differences in toxicity. Male rats also have physiological differences such as alpha2-microglobulin excretion which is not occurred on female rats (Woolley, 2003). There are major different between individuals in reaction on chemical materials because of genetic polymorphism (Eaton \& Klaassen, 2003). The importance of sex-related differences on the toxic effect of MS aqueous extract is the reason why we also chose male rats in this study.

Rats, given standardized MS aqueous extract at dose 175,500 and $2000 \mathrm{mg} / \mathrm{kg}$, showed no mortality and there were signs of fatigue and sleep for male rats while only a sign of fatigue on female rats in the treatment group of $2000 \mathrm{mg} / \mathrm{kg}$ only. The sign of fatigue occurred could be due to interference of toxicants with the passage of electrical impulses down the axon. In this study, standardized MS aqueous extract interfere with the passage of sensory, motor and also integrative impulses (Stine \& Brown, 2006). However there is no information so far that can explain why standardized MS aqueous extract can cause sleepiness and maybe fatigue sign can cause sleepiness in the present study. No other toxicity symptoms could be produced by other rats. From a previous study, mitragynine (MS major biocompound) showed no evidence of tremors and convulsions in mice given at doses as high as $920 \mathrm{mg} / \mathrm{kg}$ BW (Jansen \& Prast, 1988). According to the OECD 425 test guidelines (OECD, 2001), the author not chose any dose between $500 \mathrm{mg} / \mathrm{kg}$ and $2000 \mathrm{mg} / \mathrm{kg}$ doses because of there is no other dose selection between $500 \mathrm{mg} / \mathrm{kg}$ and $2000 \mathrm{mg} / \mathrm{kgdoses}$. However, if the dosage is increased in certain increments, data collection would be more informative based on the data collection in the present study.

The standardized MS aqueous extract did not affect the body weight, amount of food taken and water intake of the treatment rats significantly when compared to the control rats for both sexes (Table 2 and Table 3 ). These results were the same as findings from acute toxicity study of the standardized methanolic extract of Mitragyna speciosa Korth in rats (Harizal et al., 2010). The increase in body weight of all groups weekly were considered normal and gradual as observed in SD rats of a similar age group in our previous studies and also other published reference (Giknis \& Clifford, 2006). The increase in body weight was in line with the increased food consumed by female rats but water intake gradually decreased in all treatment groups. In contrast, the increase in body weight for male rats was not in line with the amount of food as the values for all groups decreased gradually. The water intake value was also decreased except for the treatment groups at $175 \mathrm{mg} / \mathrm{kg}$ and $500 \mathrm{mg} / \mathrm{kg}$. The patterns of food consumed and water intake for both sexes were not same especially for water intake value which decreased in almost all of the treatment groups. Even though inhibitory patterns of the MS extract on food and water intakes were similar, their mechanism was shown to be dissociated from each other (Kumarnsit et al., 2006). This explains why the different pattern of food consumed and water intake occured. Utilization of food and water exhibited normal metabolism in the animals (Mukinda \& Syce, 2007) and this suggested that the single oral dose of standardized MS aqueous extract did not retard the growth of rats. The increment of body weight for treatment group can considered as normal when compared to control group.

Haematological parameters, MCHC for female rats at concentrations of $500 \mathrm{mg} / \mathrm{kg}$ and $2000 \mathrm{mg} / \mathrm{kg}$ were found to be significantly decreased compared to the control rats as presented in Table 4. This may result in hypochromic (hypochromia) disease because red blood cells cannot contain increased haemoglobin (Suckow et al., 2006). The immature red blood cells (include reticulocytes) are larger than red blood cells, and contain less haemoglobin in treatment group which altered parameters associated with cell size including decreased MCHC (Nancy, 2004). The other haematology parameters for female rats were not significantly different compared to male rats. In biochemical parameters as shown in Table 5, the values for all treatment rats remained normal for female rats but not for male rats. Albumin, calcium and cholesterol serum levels in male rats showed a 
significant decrease for the treatment group at $175 \mathrm{mg} / \mathrm{kg}$. The decrease of albumin and cholesterol level showed that standardized MS aqueous extract at $175 \mathrm{mg} / \mathrm{kg}$ can reduce albumin and cholesterol production in liver or damage ALB gene which is encode albumin protein (Vasudevan et al., 2011; Choy, 2001). Electrolyte disturbance caused by standardized MS aqueous extract at $175 \mathrm{mg} / \mathrm{kg}$ also influenced by low albumin level in serum (Vasudevan et al., 2011). Only at $175 \mathrm{mg} / \mathrm{kg}$, standardized MS aqueous extract has enough molecule to interact with other biochemical molecule and finally decreased albumin, calcium and cholesterol production.

Other standardized MS aqueous extract concentrations cannot decreased albumin, calcium and cholesterol level too low because of too many molecules which cannot produce good interaction with other biochemical molecule to decreased the level too much (Eaton \& Klaassen, 2003). These correlations may lead to the possibility that at a lower dose, standardized MS aqueous extract has potential as a hepaprotective, anti-calcium and anti-cholesterol agent. Hepaprotectiveeffect also can be supported by the lowest value of ALP and ALT for the treatment group at $175 \mathrm{mg} / \mathrm{kg}$ which are the indicator of liver damage. However, the present study cannot run AST test due to insufficient reagent for this parameter. Further study needs to be done for these findings as we will confirm these abnormal findings during the subacute toxicity study. Tetany or the risk of changes of excitability of excitable cell was not observed because of author not saw the symptoms happened and the level of calcium is not too low compared to control group to excitable the cell. Gross pathological examination of the treatment groups did not reveal any abnormalities, presence of lesions or changes in the colour of the internal organs and the relative organ weight was not significantly different from the control group as shown in Table 6 . The relative weight was more indicative of toxicity than absolute weight (Demma et al., 2006), which was further supported by significant biochemical findings and noticeable effect on gross and histological evaluation conducted in the treatment groups. In contrast, the relative weight results which were not significantly different from the control group in our study can be supported by other study parameters.

Standardized MS aqueous extract did not significantly alter the morphology of all organ tissues except the liver. Histological examination of the standardized MS aqueous extract treated samples of liver stained with hematoxylene and eosin ( $\mathrm{H} \& \mathrm{E})$ revealed some abnormal morphology characteristics. Figure 1 shows that standardized MS aqueous extract in all treatment groups for both sexes has steatosis on several parts in the liver. Steatosis sign was related to cholesterol level in biochemical parameters as all the treatment groups showed less values compared to control rats except for female rats at $175 \mathrm{mg} / \mathrm{kg}$ of standardized MS aqueous extract. This might be due to lipid accumulation in several parts of the liver for the treatment group instead of the blood which lowers cholesterol level. The level of steatosis is too low because it is not present for the whole organ. At only $2000 \mathrm{mg} / \mathrm{kg}$ of standardized MS aqueous extract dose in male rats, histopathology results showed centrilobular necrosis on several parts of the liver. A study conducted in the rats treated with morphine revealed necrosis, hemorrhage, sinusoidal dilatation, apoptotic body, congestion and hydrophic degeneration (Harizal et al., 2010). Morphine induced a marked decrease in the rat hepatocytes and resulted in cell death (Nogamatsu et al., 1986). The same effects are also seen in the samples from the group with the highest dose of standardized MS aqueous extract. Authors check with veterinarian and histopathology book as guidance for diagnosis of steatosis and centrilobular necrosis morphological criteria. Fatty liveror steatosiswas not proven by special staining because we don't have enough money allocation to buy special staining to prove the fatty liver.

\section{Conclusions}

In conclusion, the acute oral administration of standardized MS aqueous extract to Sprague Dawley rats did not cause any death with only two toxic symptoms at the highest dose and no significant changes in the body weight, food and water consumption. Standardized MS aqueous extract did not induce significant alterations in almost all biochemical, haematological and morphological parameters in Sprague Dawley rats with only several parts of the liver showing toxic signs. However, the decrease in MCHC, albumin, calcium and cholesterol serum levels may indicate that standardized MS aqueous extract has potential to lead to anaemia and as a hepatoprotective, anti-calcium and anti-cholesterol agent in the future.

\section{References}

Chan, K.B., Pakiam, C., \& Rahim, R. A. (2005). Psychoactive plant abuse: the identification of mitragynine in ketum and in ketum preparations. Bulletin on Narcotics, 57, 249-256.

Choy, C. N. (2001). Genetic Toxicology and Cancer Risk Assessment. New York: Marcel Dekker, Inc. http://dx.doi.org/10.1201/9780203904237

Demma, J., Gebre-Mariam, T., Asres, K., Evgetie, W., \& Engindawork, E. (2006). Toxicological study on Glinuslotoides: a traditionally used technical herb in ethiopia. Journal of Ethnopharmacology, 111, 451-457. http://dx.doi.org/10.1016/j.jep.2006.12.017 
Deng, J. F. (2002). Clinical and laboratory investigations in herbal poisonings. Toxicology, 181-182, 571-576. http://dx.doi.org/10.1016/S0300-483X(02)00484-5

Eaton, D. L., \& Klaassen, C. D. (2003). Principles of Toxicology. In C. D.Klaassen \& J. B. I. Watkins (eds.), Casarett \& Doull's Essentials of Toxicology (pp. 6-20). United States of America: The McGraw-Hill Companies.

Giknis, M. L. A., \& Clifford, C. B. (2006). Clinical Laboratory Parameters for Crl: CD(SD) Rats. USA: Charles River Laboratories.

Harizal, S. N., Mansor, S. M., Hasnan, J., Tharakan, J. K. J., \& Abdullah, J. (2010). Acute toxicity study of the standardized methanolic extract of MitragynaspeciosaKorth in Rodent.Journal of Ethnopharmacology, 131, 404-409. http://dx.doi.org/10.1016/j.jep.2010.07.013

Hinton, P. R., Brownlow, C., McMurray, I., \& Cozens, B. (2004). SPSS Explained. New York: Routledge.

Houghton, P. J., \& Raman, A. (1998). Laboratory Handbook for the Fractionation of Natural Extracts. (1st ed.). London: Chapman \& Hall. http://dx.doi.org/10.1007/978-1-4615-5809-5

James, R. C. (1985). The toxic effects of organic solvents. In P. L. Williams \& J.L. Burson (eds.). Industrial Toxicology; Safety and health applications in the workplace. New York: Van Nostrand Reinhold. pp. 230-259.

Jansen, K. L., \& Prast, C. J. (1988). Psychoactive properties of mitragynine (kratom). Journal of Psychoactive Drugs, 20, 455-457. http://dx.doi.org/10.1080/02791072.1988.10472519

Kamarudin, A. R. (2007). The misuse of drugs in Malaysia: Past and Present. JurnalAntidadah Malaysia, 1, $1-24$.

Kumarnsit, E., Keawpradub, N., \& Nuankaew, W. (2006). Acute and long-term effects of alkaloid extract of Mitragynaspeciosa on food and water intake and body weight in rats. Fitoterapia, 77, 339-345. http://dx.doi.org/10.1016/j.fitote.2006.04.006

Kumarnsit, E., Keawpradub, N., \& Nuankaew, W. (2007). Effect of Mitragynaspeciosa aqueous extract on ethanol withdrawal symptoms in mice. Fitoterapia, $182-185$. http://dx.doi.org/10.1016/j.fitote.2006.11.012

Lipnick, R. L., Cotruvo, J. A., Hill, R. N., Bruce, R. D., Stitzel, K. A., Walker, A. P., .. Myers, R. C. (1995). Comparison of the Up-and-Down, Conventional $\mathrm{LD}_{50}$, and Fixed-Dose Acute Toxicity Procedures. Food Chem. Toxicol., 33, 223-231. http://dx.doi.org/10.1016/0278-6915(94)00136-C

Matsumoto, K., Horie, S., Ishikawa, H., Takayama, H., Aimi, N., Ponglux, D., \& Watanabe, K. (2004). Antinociceptive effect of 7-hydroxymitragynine in mice: Discovery of an orally active opioid analgesic from the Thai medicinal herb Mitragynaspeciosa. LifeSciences, 74, 2143-2155. http://dx.doi.org/10.1016/j.lfs.2003.09.054

Mukinda, J. T., \& Syce, J. A. (2007). Acute and chronic toxicity of the aqueous extract of Artemisiaafra in Rodent. Journal of Ethnopharmacology, 111, 138-144. http://dx.doi.org/10.1016/j.jep.2007.02.011

Nancy, E. (2004). Hematology of the Mouse. In: J. H. Hans \& B. Gilian, P. Peter (eds.). The Laboratory Mouse. UK: Elsevier Academic Press. pp. 271-286.

Nogamatsu, K., Onho, Y., Ikebuchi, H., Takahashi, A., Terao, T., \& Takanaka, A. (1986).Morphine metabolism in isolated rat hepatocytes and its implications for hepatotoxicity. BiochemicalPharmacology, 35, 3543-3548. http://dx.doi.org/10.1016/0006-2952(86)90624-6

OECD. (2001). OECD Guidelines for Testing of Chemicals: Acute Oral Toxicity-Up and Down Procedure, 425. Paris: OECD/OEDC.

Ong, H. C., \& Nordiana, M. (1999). Malay ethno-medico botany in Machang, Kelantan, Malaysia.Fitoterapia, 70, 502-513. http://dx.doi.org/10.1016/S0367-326X(99)00077-5

Saidin, N. A., \& Gooderham, N. J. (2007). In vitro toxicology of extract of MitragynaspeciosaKorth, a malaysianphyto-pharmaceutical of abuse. Toxicology, $240, \quad$ 164-192. http://dx.doi.org/10.1016/j.tox.2007.06.045

Stine, K. E., \& Brown, T. M. (2006). Principles of Toxicology. USA: Taylor and Francis.

Suckow, M. A., Weisbroth, S. H., \& Franklin, C. L. (2006). The Laboratory Rat. USA: Elsevier Academic Press.

Suwanlert, S. (1975). A study of kratom eaters in Thailand. Bulletin on Narcotics, 27, 21-28.

Vasudevan, M., Sreekumari, S., \& Vaidyanathan, K. (2011). Textbook of Biochemistry for Medical Students. New Delhi, India: Jaypee Brothers Medical Publishers (P) Ltd.

Wiart, C. (2002). Medicinal Plants of Southern Asia. Malaysia: Prentice Hall Pearson Malaysia.

Woolley, A. (2003). A guide to practical toxicology: Evaluation, prediction and risk. USA: Taylor \& Francis. http://dx.doi.org/10.4324/9780203212851

Zakaria, M., \& Mohd, M. A. (2010). Traditional Malay Medicinal Plants. Kuala Lumpur, Malaysia: 
InstitutTerjemahan Negara Malaysia Berhad. 